\title{
Career Development and Turnover in Food and Beverage Industry
}

\author{
Lana Garcia-Martinez $^{\# 1}$, Ify Diala ${ }^{{ }_{2}}$ \\ ${ }^{\#}$ University of Phoenix Phoenix AZ, USA \\ Walden University Minneapolis MN, USA
}

\begin{abstract}
This The hospitality industry spends nearly $\$ 3.4$ billion dollars each year on training yet the turnover rate remains the highest of all United States industries. The purpose of the study was to examine the relationship between training perceptions and turnover intent. Research has shown that employees need to have a sense of self-efficacy to stay committed to the organization. A sample of 400 U.S. employees from the food and beverage industry completed a survey focused on training perceptions and turnover intent. The independent variables included participants' age, education level, tenure, and income, as well as various aspects of perceptions about the training received. The validity and reliability of the existing surveys were already established so only the Pearson coefficient analysis was necessary for each variable. The analysis resulted in weak correlations of 9 of the 15 independent variables. The results also revealed some consistent trends among the results. The findings indicated that how employees perceive the training and career development they received does affect their turnover intentions. Leaders might use the results of the study to amend and improve current training programs in the food and beverage industry. The knowledge gained from this study may also apply to other industries.
\end{abstract}

Keywords - Food, Beverage, Hospitality, Career, Development.

\section{INTRODUCTION}

In 2011, United States companies spent \$171.5 billion on employee training and development [1]. The hospitality industry alone spends nearly $\$ 3.4$ billion each year on recruitment and training [29]. Even with the enormous cost of recruitment and training, a 2011 survey of restaurant owners reported a $47 \%$ increase in employee turnover and a $49 \%$ increase in manager turnover [4]. The most significant issue the leaders of corporations in this industry face is financial loss by not taking measures to reduce these expenses [9].

The focus of the current study was to assess the relationship between employee training perceptions and turnover intent in the food and beverage industry.

\section{BACKGROUND OF THE PROBLEM}

An interest in increasing employee performance occurred at the onset of the industrial revolution, with the birth of Taylor's scientific management theory [35]. The study laid the foundation for job satisfaction theory from the early 1900s through the 21 st century. The Hawthorne studies provided further evidence that work conditions affect job performance [24]. Reference [21] expanded job satisfaction theory, stating the inconsistency between what the job is and what the worker wants the job to be causes job dissatisfaction. In 1958, as the interest in worker motivation increased, a focus on employee turnover began to pique researchers' interest with March and Simon's process model of turnover. Between 1970 and 1990, interest in how to measure the effects of employee turnover continued [14], [27], [28], [33]. In the early 1990s through 2005, researchers began to focus on the relationship between a worker's organizational commitment and turnover intent [3], [31], [32]. In 2005, the research on both employee motivation and job turnover declined, which left gaps in research and literature about job motivation and turnover intent. The objective of the current study was to fill gaps in job satisfaction, job training, and job turnover intent in the food and beverage industry. The gap is significant considering the food and beverage industry is part of the largest employment sector [5]. The food and beverage industry also has the highest voluntary turnover rates of all employment sectors [6].

\section{A. Problem \& Purpose statement}

The general problem studied was leaders of corporations might be incurring a financial loss for organizations by not developing training programs that fulfill the intrinsic emotional needs of employees. The specific problems studied were food and beverage corporations are incurring a financial loss on current training programs and losing skilled employees because traditional training does not focus on personal development. The problem was even though the amount spent each year on corporate training programs exceeds $\$ 171.5$ billion [2], voluntary turnover in the food and beverage industry continues to increase. The purpose of this quantitative research study was to assess the correlation between employee turnover intent and employees' perceptions of training and development in the food and beverage industry.

B. Theoretical Framework 
Most food and beverage organizations use bureaucratic leadership [16]. The theory behind restaurant management leadership is McGregor's Theory X management [16]. McGregor's Theory X manager assumes workers are naturally lazy and inherently dislike work [25]. A Theory $\mathrm{X}$ manager provides a narrow span of control and constantly supervises and directs [25]. The focus of the management style is task-oriented [25]. This management theory contrasts with McGregor's Theory Y, in that Theory Y managers believe worker are self-motivated and enjoy work when upholding a positive leader-worker relationship [25]. Selfmanaged teams and a family-type culture promote higher job satisfaction and higher affective commitment to organizations [16]. Using a combination of both theories provides management the ability to focus on the task as well as establish close relationships with their workers [30]. Leader can therefore keep tight control on tasks while creating relationships with their workers, which promotes job satisfaction and high levels of affective commitment [30]. The balance produces motivated employees who have a high level of job satisfaction and reduced turnover intent [3], [13], [19], [21], [24], [31], [32]. Employees have a need for emotional engagement as well as a physical need fullfillment to commit to an organization [1], [13], [20], [23].

\section{DISCUSSIONS}

The hospitality industry contains two main categories. The first category includes the arts, entertainment, and recreation. The second category includes accommodations and food services. The focus of the study was the food-service category of the industry. The historical review includes historical statistics, causes for turnover, profiles for diverse industries, and current training trends including career development. The hospitality industry is a humanresource-centric industry that directly ties to the service provided by the employee. The terms hospitality management and hospitality training are interchangeable in all these industries [8]. In the early 1900 s, the focus of human resource management in this industry was on the manager's tasks rather than on managing personnel [8]. In the middle to late 1900s, human resource management began to include personnel management and behavioral theory in strategic planning [8]. In 2009, hospitality organizations began introducing a balanced scorecard approach to human resource management [8]. This approach set up the core competencies of the Society of Human Resources Management [8]. Using a balanced scorecard introduces a dual focus that includes hard and soft management skills. The focus of hard skills is on integrating human resources policy into the operational systems of the food and beverage establishment, whereas the focus of soft skills is on an organization's employees [8].

\section{A. Industry Profile}

The hospitality industry includes two sectors because of the vast size and diversity of the industry. This section contains an outline of each type industry in the hospitality sector. The profile includes average wage for hourly employees and managers, educational levels for entry-level employment and management positions, and job descriptions.

\section{B. Accommodations and Food and Beverage Industry}

The accommodation and food and beverage industries classify into the same subsector because of industry likenesses [5]. The accommodation industry includes any organization that provides lodging for travelers, including hotels, motels, bed and breakfasts, and recreational vehicle parks [5]. The food and beverage industry includes any establishment that serves ready-to-eat food and beverages from limited service to full service [5]. Establishments serving alcoholic drinks are also part of this sector. Nonsupervisory employees in the food and beverage industry include cashiers, hosts, service personnel, and cooks. The average wage of nonsupervisory employees in the food and beverage industry is $\$ 10.92$ an hour, with an average of 25.5 hours worked per week [5]. The average wage of a restaurant manager is $\$ 48,130$ per year and a bachelor's degree is preferable but not mandatory [5]. Managers with no degree must have 1 to 5 years of experience [5].

\section{Arts and Entertainment Industry}

The second subsector of the hospitality industry includes any type of worker in the performing arts, museums, historical sites, recreational parks, amusement parks, and gambling establishments [5]. Because the leisure and hospitality industry is so diverse, the sectors separate into two subsectors. The performing arts industry has a variety of job positions that have a diverse educational level for job entry. The incomes for these positions vary greatly also. The categories of the individuals in this industry fit into three main areas of expertise. These areas are performers, production employees, and company executives. Performers in the performing arts industry include athletes, musicians, actors, and dancers. The popularity and public demand of the performer is the basis for his or her income. Most employees on the nonsupervisory level as well as the supervisory level in the performing arts industry have a bachelor's degree. Job reputation and past work experience is the basis for acquiring job entry for these types of positions.

\section{Overview of Self-Efficacy and Turnover}

Two of the leading factors in job satisfaction are job security and chance of development within the workplace. Low job satisfaction leads to a very high level of job-related stress that leads to the high turnover rate [7]. The reasons for such extraordinarily high turnover rates include low job security, low 
promotional opportunity, and poor career development [7]. Realizing self-worth or self-efficacy influences the commitment an individual has to an organization. One definition of self-efficacy is the self-worth an employee believes is present when performing job tasks. Job performance has a direct positive correlation to job satisfaction, and job satisfaction has a direct positive correlation to an employee's commitment to an organization and the intent for the employee to stay with the organization [15]. Although researchers have not shown that self-efficacy directly affects turnover rate, self-efficacy correlates to job performance that directly correlates to turnover that indicates efficacy has an indirect correlation to turnover rate.

Heavy workload, lack of job autonomy, and conflict are the most common stressors that lessen job satisfaction, which contributes to employee turnover [22]. Employees with high self-efficacy have a lower level of job stress and create a work environment that encourages employees to increase organizational commitment, thus leading to a lower turnover rate. Logic indicates career development improves employee self-efficacy and addresses the leading job stressors, thereby promoting higher employee satisfaction and resulting in improved job performance. Even though no research has indicated a direct correlation exists to training and turnover, evidence indicates that training directly correlates to job satisfaction, thus pointing to an correlation between training and turnover [9].

\section{E. Recruitment and Selection in the Food and Beverage Industry}

Recruitment practices are informal in the food and beverage industry [36]. The most common recruitment practices are referral or casual callers. Using social networking for recruitment has increased $36 \%$ since 2012 [17], [36]. The interviews are more or less informal chats rather than in-depth applicant screenings, and the interviewer looks for individuals with high-level people skills rather than technical backgrounds [36].

Recruiting managers for fine dining place emphasis on how service oriented the potential candidate is, whereas fast-food recruiters look at task skills. Casual dining recruiters look for a balance of skills that focus on both service and task [11]. Formal education is the least important consideration for all types of food and beverage recruiters. Operation performance is the sole basis for advancement, which results in promotions for many individuals not well fitted for positions as leaders, trainers, or administrators [26].

\section{F. Training Program}

The aim of training is to heighten business performance [38]. Self-efficacy is the perceived ability an employee has to engage in organizational activities [38]. Job involvement improves job-related competencies and increases self-motivation. Every employee has personal criteria that measure career success [18]. The goal of training is to meet organizational objectives through teaching and developing employees. The training programs criterion must also meet employees' personal objectives to keep employee motivation and commitment high.

Employee training and development played a major role in keeping job satisfaction high corporate training is a systematic plan to develop the human side of an organization's knowledge. Corporate executives create these plans so the training program aligns with the organization's strategies and budgets. Leaders of every organization should have a systematic process to decide what training to impose in the organization. Many reasons influence the decision making of creating an effective training program. The reasons are training needs, training goals and objectives, budget, training design, training. The key to keeping employees is to create a training program that effectively increases affective commitment as well as improves skill performance.

\section{G. Methodology}

The objective of the study was to measure the correlation between employee training perceptions and turnover intent by using statistical analysis. Data collection involved conducting a survey to measure the opinions of food and beverage employees on training and their inclination to leave the organization based on their opinions of training [12]. The employees under study ranged from hourly employees to salaried managers responsible for running a food and beverage establishment. The source of the sample of the food and beverage employees was Survey Monkey's food and beverage audience. A quantitative method was suitable to explore the correlation between employee development and intent of voluntary turnover. Because the study involved measuring correlation between variables, a quantitative research method was appropriate. Pearson's Product-moment correlation coefficient served to discover which aspects of training influence voluntary turnover and which aspects of training do not influence voluntary turnover.

The dependent variable was turnover intent. The independent variables were the participants' demographic information, including age, income, educational level, job tenure, and job position. Additional independent variables focused on opinions participants have on training and development. The study involved measuring these variables using Likerttype scale scoring. The relationship between the dependent variable (turnover intent) and the independent variables (participants' demographics and perceptions) was measurable through correlation analysis. The study involved analysing each 
independent variable through correlation analysis and a thorough review of descriptive statistical analysis.

The survey included an informed consent page and consisted of three sections that included participants' demographics, questions about training perceptions, and Jackofsky and Slocum's turnover intentions. All employees completed the survey online through Survey Monkey. The study included the SPSS software to perform data and statistical analysis and to assess the correlations of turnover intent among various independent variables. The determination of correlation was to a $95 \%$ confidence interval with a .05 margin of error. Descriptive statistics software tabulated the mean, mode, median, and frequency tables to measure intensity of the opinions.

\section{H. Data Analysis}

The data collected in this study used descriptive statistics analysis and Pearson's Product-moment correlation coefficient for analysis. The objective of the study was to discover if any relationships exist between training opinions and turnover intent. The first part of the data analysis included descriptive statistics. The statistics included mean, median, mode, and standard deviation and provided valuable information about the tendency of emotional opinions of the participants. The next phase of the data analysis involved a correlation analysis of the training opinions and turnover intent. Pearson's Product-moment correlation coefficient was the statistical method used to decide the correlation.

\section{Three Categories of Correlation}

\begin{tabular}{cc}
\hline Strength of score & $\begin{array}{c}\text { Can be positive or } \\
\text { negative }\end{array}$ \\
\hline Weak correlation & .1 to .3 \\
Medium correlation & .3 to .5 \\
Strong correlation & .5 to 1.0 \\
\hline Note. Data are from Leard Statistics (2013).
\end{tabular}

Fig. 1 Three Categories of correlation

This study involved Pearson's Product-moment correlation coefficient analysis to discover the relationship between 15 variables and turnover intent scores. The study also included frequency tables to provide analysis of each variable. The mean, median, and mode of each variable were included in the results as well. The variables studied were participant demographics such as age, education level, income, and tenure. The other variables analyzed were the participant's opinions of training that included amount of training, effectiveness of training, supervisor interaction, and employees' growth and career development. The goal of the study was to discover what aspects, if any, had a relationship with turnover intent.

\section{Survey Demographics}

A sample size of 400 is sufficient for a population exceeding 1 million. Out of the 512 returned surveys,
103 of the respondents skipped questions. The 103 surveys that skipped questions were not used because of the missing data. The 409 complete surveys met the minimum sample criteria. The sample needed for correlation analysis is 10 completed survey responses per variable analyzed. The current study had 16 variables, and a sample of at least 160 was necessary to complete a valid correlation analysis. The 409 completed surveys met the sample criteria for a correlation analysis, as well as the sample size for populations exceeding 1 million. For consistency, the data analysis included only the completed surveys.

Frequency Table for Gender

\begin{tabular}{crr}
\multicolumn{3}{c}{ Frequency Table for Gender } \\
\hline & $n$ & $\%$ \\
\hline Male & 186 & 45.5 \\
Female & 220 & 53.8 \\
Prefer not to answer & 3 & .7 \\
\hline
\end{tabular}

Fig. 2 Frequency table for gender

\begin{tabular}{lrl} 
Frequency Table for Job Position & & \\
& $n$ & $\%$ \\
\hline Hourly nonsupervisory & 181 & 44.3 \\
Nonsalaried management & 50 & 12.2 \\
Salaried management & 100 & 24.4 \\
Other & 71 & 17.4 \\
Prefer not to answer & 7 & 1.7 \\
\hline
\end{tabular}

Fig. 3 Frequency table for position

\section{J. Statistical Data}

The turnover intent score was the dependent variable used in the correlation analysis. The score ranged from 8 to 40 . The higher the score was, the higher the intent to leave the job. The median score for turnover intent was 23. The most frequent turnover score (mode) was 24, which exceeded the median score for turnover intent. The average (mean) turnover score was close to the median score at 22.902. Slightly more than $49 \%$ of the participants had a turnover intent score higher than the median, which could indicate most of the participants had at least thought about seeking other employment.

\section{K. Variables}

In the case of age, the significance was .28 , which was more than .05; thus, the researchers did not reject the null hypothesis.

In the case of education, the significance was .068, which was more than .05; thus, the researchers did not reject the null hypothesis.

In the case of tenure, the significance was .003 , which was less than .05; thus, the researchers rejected the null hypothesis.

In the case of income, the significance was .001, which was less than .05; thus, the researchers rejected the null hypothesis. 
In the case of the amount of training received, the significance was .291, which was more than .05; thus, the researchers did not reject the null hypothesis.

In the case of training effectiveness, the significance was .045 , which was less than .05 ; thus, the researchers rejected the null hypothesis.

In the case of training effectiveness, the significance was .029 , which was less than .05; thus, the researchers rejected the null hypothesis.

In the case of task assignment, the significance was .011, which was less than .05; thus, the researchers rejected the null hypothesis.

In the case of skill use, the significance was .028, which was less than .05 ; thus, the researchers rejected the null hypothesis.

In the case of opportunity to promote, the significance was .133, which was more than .05; thus, the researchers did not reject the null hypothesis.

In the case of room for professional growth, the significance was .021 , which was less than .05 ; thus, the researchers rejected the null hypothesis.

In the case of meaningful work, the significance was .001, which was less than .05; thus, the researchers rejected the null hypothesis.

In the case of supervisor feedback, the significance was .252, which was more than .05; thus, the researchers did not reject the null hypothesis.

In the case of supervisor helping with career development, the significance was .032 , which was less than .05; thus, the researchers rejected the null hypothesis.

In the case of the helpfulness of supervisor's feedback, the significance was .086 , which was more than .05; thus, the researchers did not reject the null hypothesis is accepted.

\section{Statistical Summary}

This study involved Pearson's Product-moment correlation coefficient analysis to discover the relationship between 15 variables and turnover intent scores. The study also included frequency tables to provide analysis of each variable. The mean, median, and mode of each variable were included in the results as well. The variables studied were participant demographics such as age, education level, income, and tenure. The other variables analyzed were the participant's opinions of training that included amount of training, effectiveness of training, supervisor interaction, and employees' growth and career development. The goal of the study was to discover what aspects, if any, had a relationship with turnover intent.

\section{Findings and Results}

The demographic and opinion questions were from a certified question bank created and tested by Survey Monkey These questions underwent testing for reliability, validity, and bias. Researchers used Jackofsky and Slocum's Turnover Intent questionnaire successfully in prior studies [34]; [37]. Reference [14] tested the measure of employment turnover intentions and obtained a score of $\alpha=0.83$ for thoughts of quitting questions and $\alpha=0.73$ for the intent to leave questions. The minimum standard for reliability is $\alpha=$ 0.70 , so both reliability scores exceeded minimum standards [14]. No further testing was necessary to determine reliability or validity. The correlation analysis regarding participants' demographics resulted in mixed results. Although age and educational level revealed no statistical relationship to turnover intent, tenure and income both had weak correlations to turnover intent. The study results showed the amount of training had no relationship to turnover intent, but the effectiveness of the training did have a weak relationship to turnover intent.

The perceived effectiveness of the supervisor's direct training also had a weak relationship to turnover intent. The type of training employees receive and how effective the employees perceive the training had a direct relationship with turnover intent. All the perceptions about career development held weak relationships to turnover intent except for how many promotion opportunities were available. The number of advancement opportunities held no statistical relationship to turnover intent. Assigning tasks that used employees' skills, being able to grow professionally, and the meaningfulness of the job all had a weak relationship to turnover intent, which supported the assumption that aspects of self-efficacy and self-fulfillment are necessary for employees to stay committed to an organization.

Feedback from supervisors held no statistical correlation to turnover intent, except the supervisor's helpfulness in career development. This result also validated the assumption that employees need their emotional needs met, as well as their physical needs. The results of the survey indicated personal growth was just as important to the employee as successfully learning the tasks of the present job. The results also indicated employees did not perceive the organization or the immediate supervisor as providing a training environment that encouraged personal growth. Promotion did not hold statistical significance to turnover intent, whereas ability to grow professionally did. The weak correlations indicate that no single variable would be significant enough to cause an employee to search for new employment outside the current workplace. Multiple regression analysis might have been a better choice of analysis because multiple regression analyzes relationships and among multiple variables.

\section{CONCLUSIONS}

The purpose of the study was to examine the relationship between training perceptions and turnover intent. Research has shown that employees need to have a sense of self-efficacy to stay committed to the organization. A sample of 400 U.S. employees from the food and beverage industry completed a survey focused on training perceptions and turnover intent. 
The independent variables included participants' age, education level, tenure, and income, as well as various aspects of perceptions about the training received. The validity and reliability of the existing surveys were already established so only the Pearson coefficient analysis was necessary for each variable. The analysis resulted in weak correlations of 9 of the 15 independent variables. The results also revealed some consistent trends among the results. The findings indicated that how employees perceive the training and career development they received does affect their turnover intentions. Leaders might use the results of the study to amend and improve current training programs in the food and beverage industry. The knowledge gained from this study may also apply to other industries.

\section{REFERENCES}

[1] C. P. Alderfer, Existence, Relatedness, and Growth, New York, NY: Free Press, 1972

[2] American Society for Training and Development "State of the Industry Report," Alexandria, VA, 2011.

[3] J. Authur, "Effects of human resource systems on manufacturing systems and turnover," Academy of Management Journal, 37, 670-687, 1994.

[4] D. Berta (2011) Employee turnover up at restaurants [Online]. Available: $\quad$ http://nrn.com/article/employee-turnoverrestaurants

[5] Bureau of Labor Statistics. (2012) Occupational outlook handbook

[Online].Available:http://www.bls.gov/ooh/management/foo d-service-managers.htm

[6] Bureau of Labor Statistics. (2012) Employe turnover rates [Online].

Available: http://www.bls.gov/schedule/archives/all_nr.htm

[7] A.C. Chikwe "Impact of employee turnover: The case of leisure, tourism, and hospitality industry," Consortium Journal of Hospitality \& Tourism, 14, 43-56, 2009.

[8] M. Davidson, R. McPhail, and B. Shane, "Hospitality HRM Past, present, and the future," International Journal of Contemporary Hospitality Management, 23, 498-516," 2010.

[9] A. Dadar, A. Jusoh, and A. Rasli, "Impact of training on job turnover: Evidence from contemporary literature," Interdisciplinary Journal of Contemporary Research in Business, 3, 929-940, 2011.

[10] E. Dierdorff and E. Surface, "Assessing training needs: Do work experience and capability matter?," Human Performance, 21, 28-48, 2008.

[11] D. Emenheiser, J. Clay, and R. Palakurti, "Profiles of successful restaurant managers for recruitment and selection in the US," International Journal of Contemporary Hospitality Management, 10(9), 54-63, 1998

[12] C. Frakes. (2003) Descriptive Statistics [Online]. Available: http:frakes.cs.vt.edu-5014pdf-5014DescriptiveSatats303.pdf

[13] F. Herzberg, B.Mausner, and B. Snyderman, The Motivation to Work, New York, NY: Wiley, 1959.

[14] E.F. Jackofsky and J.S. Slocum, "A causal analysis of the impact of job performance on the voluntary turnover process," Journal of Occupational Behavior, 8, 263-270, 1987.

[15] M.K. Jones, R.J. Jones, P.L. Latreille, and P.J. Sloane, "Training, job satisfaction, and workplace performance in Britain: Evidence from WERS 2004," Labour: Review of Labour, Economics, \& Industrial Relations, 139-175, 2010.

[16] D. Koutroumanis and G. Alexakis, "Organizational culture in the restaurant industry: Implications for change," Journal of
Organizational Culture, Communications, and Conflict, 13(2), 45-54, 2009.

[17] KPMG. (2012) Food and beverage industry outlook. [Online] Available:http://www.kpmg.com/US/en/IssuesAndInsights/A rticlesPublications/Documents/food-and-beverage-industryoutlook-survey-2012.pdf

[18] M.L. Kraimer, S.E. Seibert, S.J. Wayne, R. C. Liden and J. Bravo, "Antecedents and outcomes of organizational support for development: The critical role of career opportunities," Journal of Applied Psychology, 96, 485-500, 2011.

[19] R. Likert, "A technique for the measurement of attitudes," Archives of Psychology 140, 1-55, 1932

[20] R.Likert, "Motivational approach to management development," Harvard Business Review, 37(4), 75-82, 1959.

[21] E.A. Locke, The Nature and Causes of Job Satisfaction: Handbook of Industrial and Organizational Psychology, Chicago, IL: Rand McNally, 1976.

[22] L. Lu, Y. Chang, S. Yuan-Lune, "What differentiates success from strain: the moderating effects of self-efficacy," International Journal of Stress Management, 8, 369-412, 2011.

[23] A.H. Maslow, "A theory of human motivation," Psychology Review, 50, 370-396, 1943.

[24] E. Mayo, Hawthorne and the Western Electric Company: The Social Problems of an Industrial Civilisation, London, England: Routledge, 1949.

[25] D. McGregor, The Human Side of Enterprise, New York, NY: McGraw-Hill, 1960.

[26] C.Pendleton, "Fully training your food and beverage staff while reducing turnover." Indian Gaming, 23(5), 34-35, 2013

[27] L.W. Porter and R.M. Steers, "Organizational, work, and personal factors in employee turnover and absenteeism," Psychology Bulletin, 80, 151-176, 1973.

[28] J. L. Price, The Study of Turnover, Ames: Iowa State University Press, 1977

[29] L. Ray. 2012 Employeeturnover statistics. [Online]. Available: http://smallbusiness.chron .com/employeeturnover-statistics-restaurants-16744.html

[30] F. Sahin, "The mediating effect of leader-member exchange on the relationship between Theory $\mathrm{X}$ and $\mathrm{Y}$ management styles and affective commitment: A multilevel analysis," Journal of Management and Organization, 18, 159-174, 2012.

[31] A. M. Saks, "Longitudinal field investigation of the moderating and mediating effects of self-efficacy on the relationship between training and newcomer adjustment," Journal of Applied Psychology, 80, 211-225, 1995.

[32] J.Shaw, N. Gupta, and J Delery, "Alternative conceptualizations of the relationship between voluntary turnover and organizational performance," Academy of Management Journal, 48, 50-68, 2005.

[33] J. E. Sheridan and M. A. Abelson, "Cusp catastrophe model of employee turnover," Academy of Management Journal, 26, 418-436, 1983

[34] P. L. Stephens, "A Quantitative Correlation Study of Emotional Intelligence and employee Turnover Intentions in the Information Technology Workplace," Doctoral Dissertation, 2011.

[35] F. W. Taylor, The Principles of Scientific Management, New York, NY: Harper \& Brothers, 1911

[36] C. Warhurst and D. Nickson, "Employee experience of aesthetic labour in retail and hospitality," Work, Employment and Society 21, 103-120, 2007

[37] S. G. Westland, "Retaining Talent: Assessing Relationships Among project Leadership Styles, Software Development, Job satisfaction, and Turnover Intentions, Doctoral Dissertation, 2007.

[38] X. Zhao and K. Namasivayam, "Posttraining self-efficacy, job involvement, and training effectiveness, in the hospitality industry," Journal of Human Resources in Hospitality \& Tourism, 8, 137-152, 2009. 